\title{
Feeding behaviour, prey detection and capture efficiency of the copepod Acartia tonsa feeding on planktonic ciliates
}

\author{
Per R. Jonsson ${ }^{1}$, Peter Tiselius ${ }^{2}$ \\ ${ }^{1}$ Tjärnö Marine Biological Laboratory, Pl. 2781, S-452 000 Strömstad, Sweden \\ ${ }^{2}$ Kristineberg Marine Biological Station, Pl. 2130, S-450 34 Fiskebäckskil, Sweden
}

\begin{abstract}
The copepod Acartia tonsa Dana exhibits raptorial feeding behaviour when encountering planktonic ciliates. It detects individual ciliates at a distance of 0.1 to $0.7 \mathrm{~mm}$ from the first antennae, and requires no physical contact. Detection distance is correlated with prey size, and the probability of successful captures declines with distance from the first antennae. When $A$. tonsa encounters the ciliate Mesodinium rubrum, the ciliate responds with rapid swimming motion, which reduces the probability of capture. Feeding experiments, in which $A$. tonsa was offered different concentrations of planktonic ciliates, showed that ciliates were cleared at concentrations as low as $0.3 \mu \mathrm{g} \mathrm{Cl^{-1 }}$ The observed differences in clearance for planktonic ciliates (15 to $\left.86 \mathrm{ml} \mathrm{d}^{-1}\right)$ may be explained in terms of detection distance and ciliate swimming behaviour. Experiments with mixtures of ciliates and the microflagellate Cryptomonas baltica indicated that $A$. tonsa allocated more time to suspension-feeding behaviour at high concentrations of microflagellates. The potential of $A$. tonsa to switch between raptorial and suspension-feeding behaviour may be a key in explaining their ubiquity in coastal waters
\end{abstract}

\section{INTRODUCTION}

Several recent studies have pointed to the importance of planktonic ciliates as a food source for calanoid copepods (Sheldon et al. 1986, Stoecker \& Egloff 1987. Gifford \& Dagg 1988, Wiadnyana \& Rassoulzadegan 1989). Data are usually from experimental work with one, or a few, ciliate species at concentrations resembling natural nearshore values. While the functional response of microflagellates and diatoms has been elucidated in several studies (e.g. Kiørboe et al. 1985, Paffenhöfer \& Stearns 1988), only Stoecker \& Sanders (1985) have described the reaction of copepods to varying ciliate concentrations in a controlled experiment. This is an important issue since ciliates, as food source, have been allocated varying degrees of importance ranging from insignificant (Montagnes et al. 1988, Tiselius 1989) to important (Stoecker \& Egloff 1987. Gifford \& Dagg 1988, Wiadnyana \& Rassoulzadegan 1989). The abundance of ciliates must be the governing factor, to a large extent, but higher ciliate electivity might make them an important part of the copepods diet even at times of low abundance (Stoecker \& Egloff 1987).

A preference for ciliates by calanoid copepods, has previously been noted but not explained (Sheldon et al. 1986, Stoecker \& Egloff 1987). The size of the ciliate does not seem to be the reason, since most of the ciliates investigated were well above that necessary for $100 \%$ retention efficiency. Mechanoreception (Wiadnyana \& Rassoulzadegan 1989), as well as chemoreception (Stoecker \& Egloff 1987), has been suggested to account for this preference.

An obvious difference between ciliates and algae is their higher swimming velocities. Thus, one might expect the ciliate to present the copepod with a different, and strong, mechanical stimulus by distorting the ambient fluid. Mechanoreceptors have been found on many copepods (Barrientos Chacon 1980) and this sensory equipment may help them locate ciliates. The active response required for capturing individual, fastswimming ciliates is fundamentally different from typical suspension-feeding behaviours usually observed for calanoid copepods. Some studies have suggested a 
raptorial aspect of feeding behaviour in some copepods typically regarded as suspension feeders (Londsdale et a]. 1979, Paffenhöer \& Stearns 1988).

Behavioural studies are necessary in order to understand the details of feeding by copepods and to explain the numerous reports on prey selectivity and switching behaviours. Almost all studies of feeding behaviour have used microcinematography of tethered copepods with high temporal resolution allowing only short time spans $(<10$ s) to be analysed (e.g. Koehl \& Strickler 1981, Price \& Paffenhöfer 1985, Paffenhöfer \& Stearns 1988). While these techniques are necessary to study capture mechanisms, they are insufficient for studying swimming patterns, sinking times, frequency of feeding and spatial orientation. Successful attempts to follow copepod behaviour on a longer time scale have been demonstrated by Cowles \& Strickler (1983) and Buskey (1984).

In this paper we attempt to quantify the behaviour of copepods, over a longer time scale $(10 \mathrm{~min})$, when presented with ciliates and algae at various concentrations. The capture of ciliates is described with regard to distance of detection and capture efficiency. Observations of feeding behaviour are combined with experimental studies of functional response for 3 species of ciliates differing in size and swimming behaviour. We used the copepod Acartia tonsa since it is a species likely to be faced with highly variable food conditions. It is considered largely omnivorous and able to quickly respond to various food items offered to it (Dagg 1977. Kiorboe et al. 1985). Our results indicate that $A$. tonsa catches microflagellates and ciliates in 2 fundamentally different ways, and that its feeding performance might be a result of varying the time allocated to each of these 2 behaviours.

\section{MATERIAL AND METHODS}

Material. The copepod Acartia tonsa Dana was reared in laboratory cultures as described in Kiørboe et al. (1985). Adult females were held in $30 \mathrm{l}$ plastic tanks at 13 to $16^{\circ} \mathrm{C}$ and $28 \%$ salinity, and were daily fed the cryptophyte Cryptomonas (Rhodomonas) baltica (Karsten). Four species of planktonic ciliates were used in this study: Strombidium reticulatum (Leegaard), Laboea strobila Lohmann and Strobilidium (Lohmanniella) spiralis (Leegaard) all belonging to subclass Choreotrichia; and Mesodinium rubrum (Lohmann) belonging to subclass Haptoria. S. reticulatum and $S$. spiralis, were cultured as described in Jonsson (1986) with the prasinophyte Pyramimonas sp. as food. Seawater samples containing the autotrophic ciliate $M$. rubrum were enriched with $\mathrm{f} / 2$ medium (Guillard 1975), and incubated at $12^{\circ} \mathrm{C}$ in a 16 h light: 8 h dark cycle $\left(190 \mu \mathrm{E} \mathrm{m}^{-2} \mathrm{~s}^{-1}\right)$. Individuals of $L$. strobila were collected from samples of natural seawater. Batch cultures of $C$. baltica and Pyramimonas sp. were grown in enriched seawater (medium $\mathrm{f} / 2$ ) at $12^{\circ} \mathrm{C}$ in a $16 \mathrm{~h}$ light: $8 \mathrm{~h}$ dark cycle $\left(190 \mu \mathrm{E} \mathrm{m}^{-2} \mathrm{~s}^{-1}\right)$. Approximate size and volume of the 4 ciliate species are shown in Table 1. Cell volume of all ciliates, except $L$. strobila, was measured on an Elzone 80xy particle counter (Particle Data Inc., USA). The volume of $L$. strobila was calculated from linear dimensions of cells fixed in osmium tetroxide $(1 \% \mathrm{w} / \mathrm{v})$. For conversion of ciliate volume to carbon, a factor of 0.071 was used (Fenchel \& Finlay 1983). Carbon content of C. baltica was assumed to be $37 \mathrm{pg} \mathrm{C} \mathrm{cell}^{-1}$ (Kiørboe et al. 1985).

Feeding experiments. Glass bottles $(620 \mathrm{ml})$ or polycarbonate bottles $(2355 \mathrm{ml}$ ) were filled with filtered (Millipore CWSS TP, ca $0.3 \mu \mathrm{m}$ ) and autoclaved seawater ( $28 \%$ ). To ensure survival of ciliates it was necessary to add EDTA (ethylenediaminetetraacetate, $10 \mu \mathrm{M})$ to the filtered seawater. Individually picked females of Acartia tonsa were added to 4 replicate bottles to yield a concentration of 11 copepods $1^{-1}$. Ciliates, offered as prey, were then added individually or as volumes of stock culture of known concentration. Before screw-caps were tightened, plastic film was placed over the mouth of the bottle to prevent bubble formation. Two controls, with ciliates but without copepods, were included. Experimental bottles were then rotated at $0.2 \mathrm{rpm}$ at $14^{\circ} \mathrm{C}$ in dim light $(12 \mathrm{~h}$

Table 1 Approximate cell length (excluding clla; $\mu \mathrm{m})$, width $(u m)$, volume $\left(u \mathrm{~m}^{3}\right.$, mean $\left.\pm \mathrm{SD}\right)$ and carbon (pg) of 4 ciliate species

\begin{tabular}{|lcccc}
\hline Species & Length & Width & Volume & Carbon \\
\hline Strobilidium spiralis & 65 & 65 & $1.5 \times 10^{5} \pm 3 \times 10^{4}$ & $1.1 \times 10^{4}$ \\
Laboea strobila & 130 & 65 & $1.4 \times 10^{5} \pm 4 \times 10^{4}$ & $9.9 \times 10^{3}$ \\
Strombidium reticulatum & 43 & 30 & $1.6 \times 10^{4} \pm 5 \times 10^{3}$ & $1.1 \times 10^{3}$ \\
Mesodinium rubrum & 43 & 38 & $3.0 \times 10^{4} \pm 8 \times 10^{3}$ & $2.1 \times 10^{3}$ \\
a Measured by Elzone particle counter & & & \\
balculated from linear dimensions & & & \\
c Converted from volume assuming a factor of 0.071 (Fenchel \& Finlay 1983) & \\
\hline
\end{tabular}


light: $12 \mathrm{~h}$ dark at $0.3 \mu \mathrm{E} \mathrm{m} \mathrm{m}^{-2} \mathrm{~s}^{-1}$ ) for $24 \mathrm{~h}$. At the end of each experiment the content of all bottles was poured through a $200 \mu \mathrm{m}$ mesh sieve to determine the number and condition of copepods. Mortality of females was insignificant $(<1 \%)$. The entire content was then preserved with Lugol's acid iodine solution and filtered down on $25 \mathrm{~mm}$ filters with $3 \mu \mathrm{m}$ pore size (Sartorius SM11302). Filters were placed on slides in a drop of immersion oil and numbers of ciliates were counted under a microscope (Olympus BH-2, 125×). Clearance (volume cleared of prey per unit time) was calculated from difference between treatment and control bottles according to Frost (1972).

Since Strombidium reticulatum and Strobilidium spiralis were reared on an algal diet, various amounts of Pyramimonas sp. were inevitably present among ciliates in the experiments. The concentrations of algae

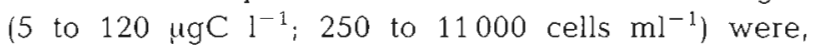
however, below the level where Acartia tonsa shows maximum clearance for algae of similar size (Kiorboe et al. 1985). In addition, we found no significant (t-test, $\mathrm{p}>0.05$ ) difference in clearance for ciliates at 0.55 and $1.1 \mathrm{\mu gCl}^{-1}$ (500 and 1000 ciliates $\mathrm{l}^{-1}$ ) when ciliates were offered together with algae or as sole prey (individually picked). Thus we conclude that the copepods responded to variations in ciliate concentrations and not to correlated variations in algal concentrations.

Behaviour of Acartia tonsa. Behaviour of Acartia tonsa in a small aquarium (ca $10 \times 10 \times 2.5 \mathrm{~cm}$ ), placed in a stirred water bath, was observed with a horizontally mounted dissecting microscope (Wild M5A, 12 to $25 \times$ ) equipped with a video camera (Panasonic CCDF10). The camera shutter speed (ca $1 \mathrm{~ms} \mathrm{frame}^{-1}$ ) and the video-recorder (Panasonic NV-180) provided a time resolution of $40 \mathrm{~ms}$ between frames. The temporal resolution was too low to observe capture movements of the feeding appendages but sufficiently high compared to the length of feeding bouts (Table 3). Capture of small (6 $4 \mathrm{~m}$ equivalent sphere diameter) microalgae was impossible to observe in our video films but we assume that this happened when $A$. tonsa created feeding currents (Rosenberg 1980, Cowles \& Strickler 1983). The aquarium holding copepods was illuminated from behind with a cold light source $(150 \mathrm{~W}$ halogene lamp) resulting in a light intensity of 50 to $80 \mu \mathrm{E} \mathrm{m}^{-2} \mathrm{~s}^{-1}$. Sinking velocity of $A$. tonsa was measured by tracing sinking individuals, frame by frame, on a plastic sheet covering the monitor screen. Feeding currents generated by free-swimming $A$. tonsa were followed and measured in a similar way by tracing particles moving along flow lines.

To construct a simple time budget, the activities of Acartia tonsa were divided into 2 categories; 'sinking behaviour' when no movement of appendages could be observed, and 'active behaviour' when copepods showed bursts of swimming with first antennae or movement of feeding appendages. Recorded sequences were analysed by counting the number of frames showing 'active behaviour' and designating the rest as 'sinking behaviour'. In a series of experiments, time budgets were calculated for copepods exposed first to ciliates (Strombidium reticulatum, $11 \mu \mathrm{gC}^{-1}$ ) and then to high concentrations of Cryptomonas baltica (1100 to $1400 \mathrm{ugCl}^{-1} ; 3 \times 10^{4}$ to $3.8 \times 10^{4} \mathrm{cells} \mathrm{m}^{-1}$ ). In a second series of experiments, time budgets were calculated for 1 female which was initially exposed to filtered seawater, then to ciliates ( $S$. reticulatum, $11 \mathrm{\mu gC}^{-1}$ ) followed by additions of increasing concentrations of $C$. baltica $\left(11,110,330\right.$ and $\left.1100 \mathrm{ugCl}^{-1}\right)$ and finally back to the ciliate treatment again. Differences in the allocation of the 2 types of behaviours between treatments were analysed using a test for equality of 2 frequencies (Sokal \& Rohlf 1969).

Prey detection and capture efficiency by Acartia tonsa, feeding on different species of ciliates, were observed with video-recording equipment (as described above) fitted to a dissecting microscope (Wild M5A with dark field, $12 \times$ ), now mounted vertically. Female copepods and ciliates were placed in a $10 \mathrm{ml}$ sedimentation counting chamber, filled with seawater and sealed on top with a coverslip. Recorded sequences where copepods showed detection of approaching ciliates and subsequent capture behaviour were analysed frame by frame allowing measurements of detection distance and capture efficiency. Detection of prey was defined as the instant when the copepod started to move towards the prey or when feeding appendages started to create a flow entraining the prey. To study detection and capture of chemically inert prey we exposed $A$. tonsa to $76 \mu \mathrm{m}$ latex beads. When $A$. tonsa approaches the ciliate Mesodinium rubrum, the ciliate often reacts by rapidly swimming away. Swimming velocity during these swift 'jumps' was measured as described above for sinking velocity of $A$. tonsa.

\section{RESULTS}

\section{Feeding experiments}

The results of the feeding experiments are shown in Fig. 1. Acartia tonsa cleared the offered ciliates at different rates with the highest rate for Strobilidium spiralis (max. $86 \mathrm{ml} \mathrm{d}^{-1}$ ) and the lowest rate for Mesodinium rubrum ( $\max .15 \mathrm{ml} \mathrm{d}^{-1}$ ) with an intermediate rate for Strombidium reticulatum (max. $47 \mathrm{ml} \mathrm{d}^{-1}$ ). Clearance decreased for $S$ reticulatum at low concentrations, and no ingestion of ciliates could be detected at $0.1 \mu \mathrm{gC}^{-1}$ $\left(100\right.$ cells $\left.^{-1}\right)$. The functional response of $A$. tonsa, when 


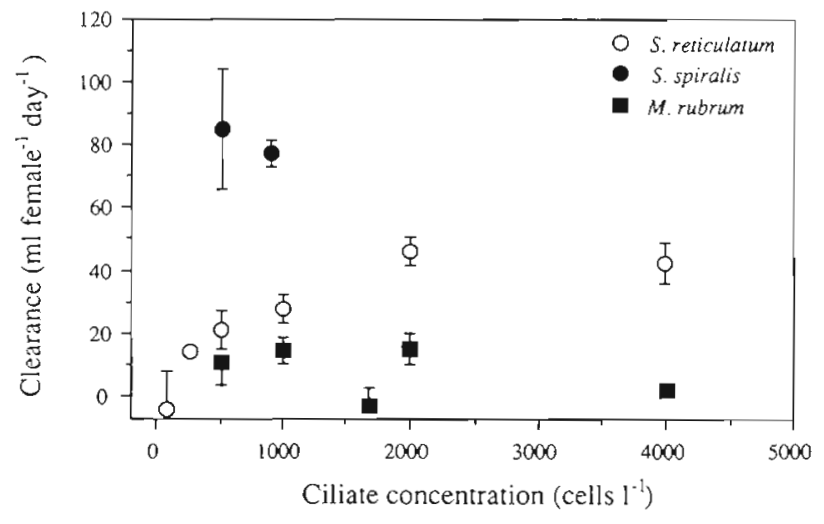

Fig. 1. Acartia tonsa. Clearance (mean $\pm \mathrm{SE}$ ) of females for three species of ciliates, as a function of ciliate abundance

offered $M$. rubrum, was not well defined. No saturation of feeding rates was found at the prey concentrations used.

\section{Behaviour of Acartia tonsa}

Observations of free-swimming Acartia tonsa revealed 2 fundamentally different types of feeding behaviour. In low to moderately high food concentrations ( $\leq 230 \mu \mathrm{g} \mathrm{Cl^{-1 }}$ ), copepods mostly sank passively, often starting with a horizontal body orientation and a mean sinking velocity of $0.58 \pm 0.1 \mathrm{~mm} \mathrm{~s}^{-1}$ $( \pm \mathrm{SE}$ ). Due to asymmetries of the body, a torque tended to align the copepod along the vertical axis, reaching a terminal sinking velocity of $0.80 \pm 0.21$ $\mathrm{mm} \mathrm{s}^{-1}$. About each second, A. tonsa darted upwards by a thrust of its first antennae (and sometimes the thoracopods), lasting about $0.1 \mathrm{~s}$. When a sinking copepod detected a prey its body is rapidly reoriented towards the point of detection, and capture of the prey was attempted by creating a strong water-flow towards

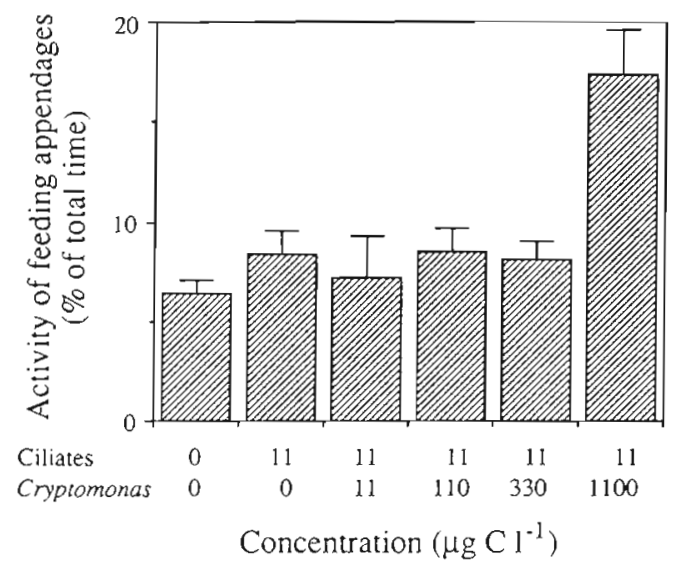

Fig. 2. Acartia tonsa. Time budget showing fraction of time (mean \pm SE) allocated to movements of feedings appendages in mixtures of the ciliate Strombidium reticulatum and the cryptophyte Cryptomonas baltica
Table 2. Acartia tonsa. Fraction of time of mouthpart movements in females exposed to the ciliate Strombidium reticulatum (11 $\mu \mathrm{gC} \mathrm{l}^{-1}$ ) or high concentrations (1100 to 1400 $\mu \mathrm{gC}^{-1}$ ) of the cryptophyte Cryptomonas baltica

\begin{tabular}{|c|c|c|}
\hline \multirow[t]{2}{*}{ Female } & \multicolumn{2}{|c|}{ Activity ( $\%$ of total time) } \\
\hline & S. reticulatum & C. baltica \\
\hline I & 11.3 & 30.2 \\
\hline II & 8.5 & 17.2 \\
\hline III & 8.3 & 17.4 \\
\hline
\end{tabular}

the mouth region using movements of the mouthparts. The mouthparts move only during, and some seconds after, a successful capture. Occasionally, A. tonsa moves its mouthparts for about half a second, without apparently approaching prey. During raptorial feeding a time budget shows that first antennae and mouthparts moved about 5 to $10 \%$ of the total time, leaving the rest to passive sinking (Fig. 2, Table 2).

When the concentration of Cryptomonas baltica is successively increased, Acartia tonsa will at some threshold between 330 and $1100 \mu \mathrm{g} \mathrm{Cl} \mathrm{l}^{-1}$ more than double the time devoted to movements of mouthparts (Fig. 2, Table 2), During this apparent suspension feeding behaviour, $A$. tonsa did not reorient its body and the feeding bouts were similar both in length of time and appearance (Table 3). Measurements of flow velocities generated by the beating mouth parts during suspension feeding were used to construct the diagrammatic flow field around $A$. tonsa shown in Fig. 3. The flow field is ventrally directed and reaches velocities of more than $8 \mathrm{~mm} \mathrm{~s}^{-1}$ in the vicinity of the second maxillae. It drops to $4 \mathrm{~mm} \mathrm{~s}^{-1}$ at a distance of ca $0.5 \mathrm{~mm}$ from the capture area. A. tonsa could rapidly switch to the raptorial feeding mode if large prey was detected during suspension feeding on $C$. baltica.

Table 3. Acartia tonsa. Duration (mean $\pm \mathrm{SD}$ ) of feeding bouts and sinking of females at $1100 \mu \mathrm{gC} \mathrm{l}^{-1}$ of Cryptomonas baltica. No. sequences analysed in parentheses

\begin{tabular}{|lc|}
\hline Female & Duration $(\mathrm{ms})$ \\
\hline Feeding & $297 \pm 258(100)$ \\
Sinking & $572 \pm 856(101)$ \\
\hline
\end{tabular}

\section{Detection and capture of prey}

When a ciliate approaches a passively sinking Acartia tonsa the ciliate is detected from a distance of 0.1 to $0.7 \mathrm{~mm}$ to the first antennae. Most reactions did not involve physical contact with antennae or setae. Upon detection, the copepod rapidly reorients its body 

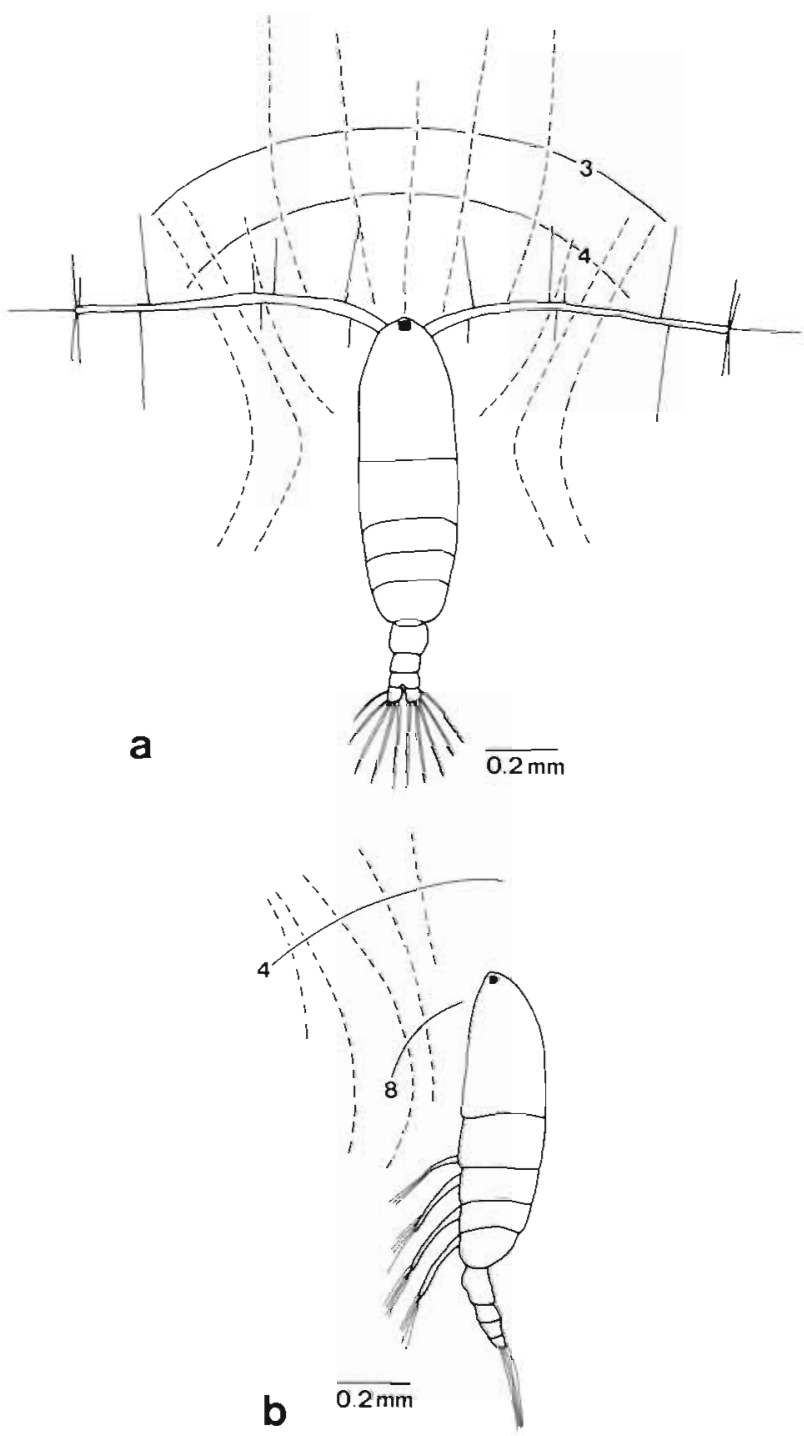

Fig. 3. Acartia tonsa. Diagrammatic flow field. Dashed lines. flow lines; continuous lines; velocity isolines $\left(\mathrm{mm} \mathrm{s}^{-1}\right)$. (a) Dorsal view; (b) lateral view

towards the point of detection and capture of the ciliate is attempted by movements of second antennae, thoracopods and second maxillae which intercept the ciliate in a successful capture. The whole sequence of events takes less than $0.1 \mathrm{~s}$. The detection distance is significantly shorter for the smaller Strombidium reticulatum than for the larger Laboea strobila (t-test, $\mathrm{p}<0.01$ ), both normal to and along the first antennae (Fig. 4). It is also obvious from Fig. 4 that the probability of missing detected prey increases with distance. When A. tonsa is offered Mesodinium rubrum as prey, capture efficiency is significantly lower than for the other 2 ciliates (Chi-square, $\mathrm{p}<0.002$ ). This is explained by the different swimming behaviours of the 3 ciliate species. S. reticulatum and L. strobila swim in a spiral motion with more or less constant speed ca 0.5 to $1 \mathrm{~mm}$ $\mathrm{s}^{-1}$, occasionally interrupted by short ciliary reversals (backward swimming). In contrast, $M$. rubrum is immobile for some seconds and suddenly swims very rapidly for less than a second. These swift 'jumps' are also elicited by approaching objects, e.g. copepods, and $M$. rubrum reaches ca $8.5 \mathrm{~mm} \mathrm{~s}^{-1}$ which equals or exceeds the flow velocities generated by $A$. tonsa during movements of mouthparts (Fig. 3).

Acartia tonsa apparently responded only to swimming objects in the vicinity of the antennae since sinking, $76 \mu \mathrm{m}$ plastic beads could hit the antennae without any reaction (Fig. 4d). The captured beads were caught in the feeding current while the copepod moved its feeding appendages and their capture is not attributed to actual detection-attack response. The beads were only briefly handled and then rejected.

\section{Handling time}

The mouthparts move only during the capture attempt and some seconds after a successful capture. The duration of post-capture movements of mouthparts which was correlated to prey size was $0.64 \pm 0.16 \mathrm{~s}$ (mean $\pm \mathrm{SD})$ for Strombidium reticulatum $(\mathrm{n}=12)$, $0.77 \pm 0.30 \mathrm{~s}$ for Mesodinium rubrum $(\mathrm{n}=12)$ and $1.36 \pm 0.5 \mathrm{~s}$ for Laboea strobila $(\mathrm{n}=21)$. In a few cases when $A$. tonsa was observed to capture large Didinium sp., movements of mouthparts continued for several seconds. This indicates that post-capture movements of mouthparts reflect handling time of prey.

\section{DISCUSSION}

Most studies on feeding activity of Acartia tonsa report clearing rates based on disappearance of particles during incubation. This indirect method gives no indication of how the various rates occur. Often, when trying to explain differences in clearance, phenomena like prey selectivity and retention efficiency are inferred. An understanding of the underlying mechanisms determining clearance for a specific prey requires insight in the predation process including predator behaviour and prey escape responses (Ohman 1988, Price 1988).

\section{Feeding rates}

Clearance rates of Acartia tonsa for the ciliates Strobilidium spiralis and Strombidium reticulatum are similar to reports from previous feeding experiments where A. tonsa was offered ciliates as food (Stoecker \& 

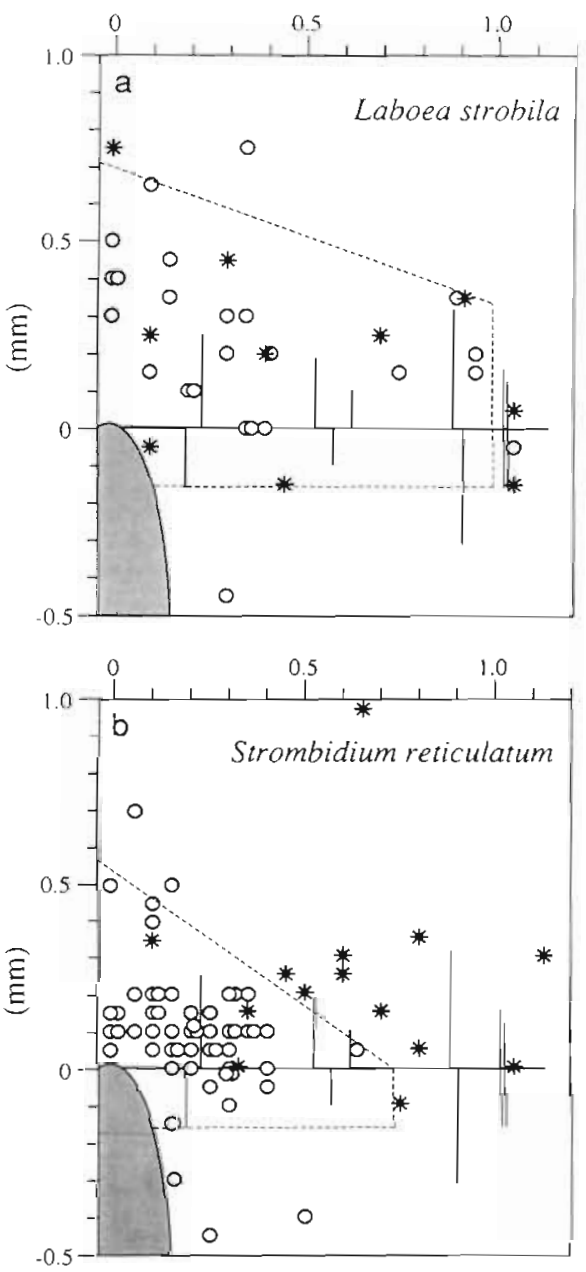
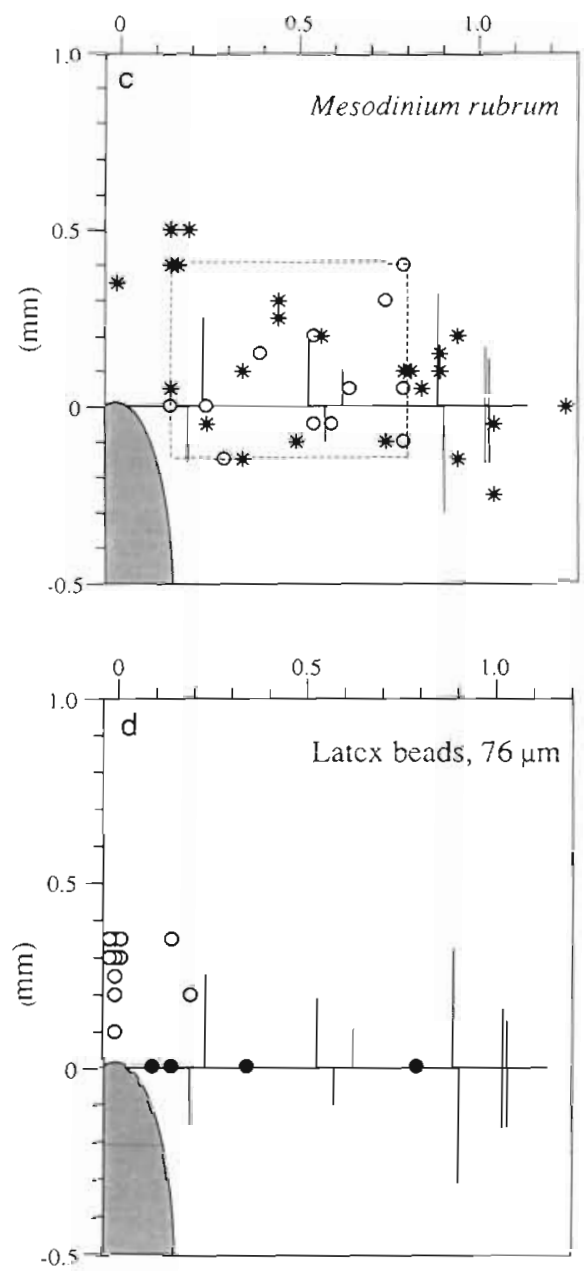

Fig. 4. Acartia tonsa. Attack field when exposed to 3 ciliate species and inert latex beads. Diagrams show the first antenna with setae and position of prey when attacked by the copepod. Dashed polygons mark the projection of capture volume defined in the text. (o) Successful capture; (*) miss of prey; ( $\bullet$ collision of beads with antennae without response. (a) Laboea strobila (b) Strombidium reticulatum; (c) Mesodinium rubrum; (d) Latex beads, $76 \mu \mathrm{m}$

Egloff 1987). A. tonsa cleared ciliates at relatively high rates even down to very low food concentrations.

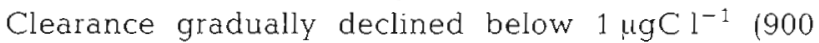
cells $\mathrm{I}^{-1}$ ) of $S$. reticulatum and ceased completely at $0.1 \mu \mathrm{gC} \mathrm{l}^{-1}$. This rather low feeding threshold might be expected when prey size increases (Price \& Paffenhöer 1985). Food concentrations below the feeding threshold are probably rarely encountered by the neritic A. tonsa, but may limit its possibilities to exploit offshore environments where food levels are low (Paffenhöer \& Stearns 1988). Differences in clearance between different prey have been found in many studies; $A$. tonsa clears ciliates ca 5 to 10 times more efficiently than microflagellates and small diatoms (Stoecker \& Egloff 1987, Gifford \& Dagg 1988) and adult $A$. tonsa has higher clearance for large than for small ciliates (Stoecker \& Egloff 1987, Tiselius 1989). In the present study $A$. tonsa cleared $S$. spiralis more than
6 times as efficiently as Mesodinium rubrum. We suggest that these differences may be explained by the behaviours of copepods and its prey.

\section{Feeding behaviour}

In our experiments, $A$. tonsa exhibited 2 types of feeding behaviour. In low to moderately high food concentrations, copepods sink passively in search for large prey which are remotely detected and captured individually At high algal food concentrations, feeding behaviour switched to more typical suspension feeding with 20 to $30 \%$ of the time allocated to movements of feeding appendages. Similar low feeding activity was found for A. clausi by Gill (1987) which contrasts with other investigated copepod species, where time allocated to movements of feeding appendages exceeds 
$50 \%$ (Gill 1987). This difference may be real and may indicate that $A$. tonsa generally allocates less time to suspension feeding. However, we can not exclude the possibility that the use of white light of high intensity in our experiments reduced feeding activity as reported by Stearns (1986).

The observed switching of feeding behaviour has considerable significance when discussing the mechanisms determining clearance for different prey. It is obvious that clearance in the 2 feeding modes is determined by very different components. When Acartia tonsa feeds on abundant and small prey, mouth parts generate a water flow from which prey are extracted by the second maxillae, obviously without any perception of individual cells (Paffenhöfer \& Stearns 1988). Although the actual mechanism of particle retention in copepods is still inadequately understood (e.g. Cheer \& Koehl 1987), clearance (F) of small cells by $A$. tonsa may be viewed as the product of water flow passing the second maxillae (Q) and the retention efficiency (E) for that particular prey, i.e.,

$$
F=Q \quad E
$$

This model can be elaborated to include variations in retention efficiency as a function of prey size and shape, handling time of prey and any dependence of food concentration on clearance. Clearance of $A$. tonsa may, appropriately, be described by this model when it feeds on small prey. The reconstruction of the flow field in Fig. 3 allows a rough calculation of water flow passing the second maxillae. Total flow can be calculated as flow velocity $\left(4 \mathrm{~mm} \mathrm{~s}^{-1}\right)$ multiplied by the area of the $4 \mathrm{~mm} \mathrm{~s}^{-1}$ isosurface limited by the critical flow lines representing the outermost flow available to the second maxillae. The isosurface is about $0.4 \mathrm{~mm}^{2}$ if it is considered as a segment of a half sphere since flow is asymmetrical and occurs mainly on the ventral side. This simplistic calculation yields a clearance of $40 \mathrm{ml}$ $\mathrm{d}^{-1}$, assuming that retention is complete and that $30 \%$ of the time is spent feeding (Table 2). This is somewhat lower than rates found by Berggreen et al. (1988) for larger diatoms. For small flagellates, like Cryptomonas baltica, clearance is lower suggesting low rentention efficiencies. Apart from differences in retention efficiency between prey our video recordings show that clearance will be influenced by the time allocated to suspension feeding and sinking (Fig. 2).

Clearance during raptorial feeding must be explained in other terms. In the case of Acartia tonsa, our interpretation is that the sinking copepod is sampling the environment with its first antennae which have the ability to detect prey from some distance. The observations of detection and capture of ciliates (Fig. 4) show that prey may be detected at a distance of more than $0.7 \mathrm{~mm}$ to the first antennae. The ability to sense prey from such distance may either be due to mechanoreceptors that perceive fluid disturbances caused by moving prey, or perception by chemoreception of molecules diffusing through the boundary layer of the prey. Chemoreception is probably important during handling and rejection of prey (e.g. Cowles et al. 1988). Buskey (1984) showed that chemoreception of exudates may give copepods general information about food abundance, guiding the copepod in search for food patches. However, Légier-Visser et al. (1986) argued that chemical gradients will rapidly fall below background levels and are unlikely to play a role in remote detection. Support for the use of mechanoreceptors comes from Barrientos Chacon (1980) who found that e-type sensory hairs, which are thought to function as mechanoreceptors, are particularly numerous on the first antennae in Acartia spp. when compared to other species. Experiments where A. tonsa was exposed to $76 \mu \mathrm{m}$ latex beads (Fig. $4 \mathrm{~d}$ ) show that detection of prey must be a complex response. Only rarely did the copepods respond, even when beads collided with the first antennae or antennal setae, and capture was often unsuccessful. It may be speculated that copepods perceive the difference between remote fluid disturbances of passively sinking and swimming objects (Roberts 1981) and hence hydrodynamic signals from latex beads are interpreted as uninteresting. Hopefully, future studies of neurophysiological mechanisms will shed more light on how prey detection functions in copepods.

The experiments on detection distance and capture efficiency indicated that both detection distance and the proportion of successful captures varies among the 3 ciliates (Fig. 4). It is obvious that capture efficiency decreases with distance from first antennae for the 3 species. If mechanoreceptors on the first antennae are responsible for remote prey detection it is reasonable to assume that the fluid disturbance caused by an approaching prey will be weaker with increasing distance (Kirk 1985, Légier-Visser et al. 1986). A weak signal may contain insufficient information about the location of the prey which is missed by the copepod. By similar arguments, a larger prey should emit stronger signals which should increase the capture efficiency for a given distance. The marked drop in capture efficiency with distance for Strombidium reticulatum compared to Laboea strobila may reflect the 5-fold-difference in size between the 2 ciliates. If a polygon is drawn in Fig. 4, so as to include at least $95 \%$ of the detection points where capture was successful, this defines a 2-dimensional projection of what may be termed the capture volume (note that this projection will underestimate the real 3dimensional detection distances). The probability of successful captures, or capture efficiency, within this volume is assumed to be the number of captures divided 
by total detection events. If we assume that the capture volume has a circular cross section, and that sinking velocity of Acartia tonsa is the mean for horizontally and vertically oriented copepods, we can construct a model where clearance $(F)$ is a function of the cross sectional area (A) of the capture volume, copepod sinking velocity (U) and the probability that an attacked ciliate is captured (E), i.e.,

$$
\mathrm{F}=\mathrm{A} \cdot \mathrm{U} \quad \mathrm{E}
$$

This model assumes that all ciliates within the capture volume are detected and attacked (e.g. no feeding threshold). It also assumes that diffusion deposition due to ciliate motility is small (computer simulations showed that this mechanism may account for less than $5 \%$ of captured ciliates). With this model we can com. pare the results from the feeding rate experiments with observations of feeding behaviour. Cross sectional area of the capture volume and capture efficiencies for the tested ciliates are listed in Table 4 giving a calculated clearance of $36 \mathrm{ml} \mathrm{d}^{-1}$ for Strombidium reticulatum and $65 \mathrm{ml} \mathrm{d}^{-1}$ for Laboea strobila. The expected clearance for $S$. reticulatum is reasonably close to what was found in the feeding experiments. Unfortunately, no data is available on clearance of Acartia tonsa for L. strobila. However, we measured clearance for Strobilidium spiralis which is comparable in size to $L$. strobila. Assuming that $S$. spiralis is representative for ciliates of similar size, calculated clearance for $L$. strobila compares well with that actually found for $S$. spiralis. Observations of A. tonsa when feeding on Mesodinium rubrum revealed that this ciliate has an impressive ability to escape capture. Either it responds to the approaching copepod and swims away rapidly before it is detected by the copepod or it escapes in the short time interval between detection and attempted capture (Fig. $4 \mathrm{c}$ ). A. tonsa did not have a higher probability of catching this ciliate closer to the body as was the case with $S$. reticulatum and L. strobila. A successful capture is therefore, likely to be a result of whether or not the ciliate 'escapes' away from the copepod or towards its second maxillae. The maximum flow velocity created by $A$. tonsa at capture is sufficient to catch $S$.

Table 4. Acartia tonsa. Volume of water cleared (Vol., ml female ${ }^{-1} \mathrm{~d}^{-1}$ ) of ciliates based on sinking velocities, cross sectional area (CSA, $\mathrm{mm}^{2}$ ) of capture volume and capture efficiency $(C E, \%)$. Sinking velocity is the average of velocities with body honzontal and vertical $\left(0.69 \mathrm{~mm} \mathrm{~s}^{-1}\right)$

\begin{tabular}{|lccc|}
\hline Ciliate & CSA & CE & Vol. \\
\hline Laboea strobila & 1.45 & 75 & 65 \\
Strombidium reticulatum & 0.64 & 94 & 36 \\
Mesodinium rubrum & 0.72 & 48 & 20 \\
\hline
\end{tabular}

reticulatum and $L$. strobila but too weak to efficiently catch $M$. rubrum. Calculated clearance from observed detections and captures of $M$. rubrum is $20 \mathrm{ml} \mathrm{d}^{-1}$ (Table 4), which is slightly higher than what was found in the feeding experiments. Note, however, that the model does not account for any escape of prey before it is detected by the predator, and consequently the model will overestimate clearance for $M$. rubrum if predetection escape occurs.

\section{Prey behaviour}

The present study suggests that escape responses by prey will significantly reduce clearance of Acartia tonsa. Many ciliate species and other microzooplankton e.g. nauplii show distinct escape responses upon mechanical disturbance. Escape responses are often. less dramatic than that of Mesodinium rubrum but we suggest that even a modest ability to increase swimming speed when approached by a predator will reduce the risk of predation. In particular, this may apply when the predator is a copepod species which does not show chase and capture response allowing prey to escape before they are entrained in the feeding currents. Considering the potentially complex interactions between predator and prey behaviour outlined above it will be difficult to infer electivity of prey from mere measurements of clearance.

\section{Ecological considerations}

Acartia tonsa is not a representative true suspensionfeeding copepod since it engages in suspension feeding only a small fraction of the time (Table 2), whereas a typical suspension-feeder like Paracalanus sp. allocates $>80 \%$ of the time to this feeding mode (Paffenhöfer \& Stearns 1988). Furthermore, A. tonsa is unable to change the flow-field or to sense individual cells displaced towards it (Paffenhöfer \& Stearns 1988). We observed that sinking behaviour is not only a way to scan the water column for algal food patches (Strickler 1982) but also an active feeding mode for catching larger and/or moving prey, such as ciliates. The long antennal setae typical of Acartiidae are thought to be involved in mechanoreception (Barrientos Chacon 1980) and are crucial to the copepods' ability to sense prey while sinking. The sensory hairs are orientated in such a way as to create a large cross sectional area at all angles (Fig. 5), therefore, they are not dependent on a directed flow of water for optimal function. They sense a relatively large volume of water which is essential when moving prey is to be detected without any movements by the predator. Other copepod species have 


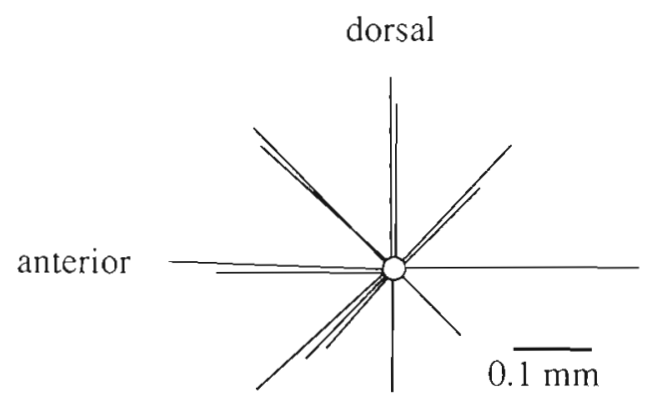

Fig. 5. Acartia tonsa. Diagram of the first antenna, viewed from the side, showing orientation of setae

much shorter setae and do not display the same type of swimming behaviour as Acartia sp. It appears that Acartia sp. is at an advantage over other copepod species since it is also actively searching the water at times of sinking. While other species have to create a feeding current to sense the environment $A$. tonsa is able to do so without any movements.

The apparent ability to switch between 2 feeding modes might be selectively advantageous in environments with great variations in prey size and abundance, which is typical of coastal waters. Although Acartia tonsa, in our experiments, switched to suspension feeding only at very high food concentrations this threshold may be lower under natural conditions. This would allow $A$. tonsa to exploit larger moving prey by raptorial behaviour and smaller or non-motile prey by suspension feeding according to their abundance. Previous findings by Stoecker \& Egloff (1987) that $A$. tonsa cleared ciliates at lower rates at high algal concentrations may be interpreted as a switch of feeding behaviour. If $A$. tonsa is able to alter its behaviour tracking variances in food composition this might be a key to explain their ubiquity in coastal waters.

Acknowledgements. We thank Hans Dam, Thomas Kiorboe and Peter Verity for critically reading the manuscript. This work was supported by the Swedish Natural Science Research Council through contract B-BU 1860-301 and by the Colliander Foundation to P.R. J. and by the National Swedish Environment Protection Board (grant no. 53112337-8) and by the Hierta-Retzius Foundation to P. T

\section{LITERATURE CITED}

Barrientos Chacon, Y (1980). Ultrastructure of sensory units of the first antennae of calanoid copepods. M. Sc. thesis, University of Ottawa, Ontario

Berggreen, U., Hansen, B., Kiørboe, T (1988). Food size spectra, ingestion and growth of the copepod Acartia tonsa during development; implications for determination of copepod production. Mar. Biol. 99: 341-352

Buskey, E. J. (1984). Swimming pattern as an indicator of the roles of copepod sensory systems in the recognition of food. Mar. Biol. 79: 165-175
Cheer, A. Y L., Koehl, M. A. R. (1987). Paddles and rakes: fluid flow through bristled appendages of small organisms. J. theor. Biol. 129: 17-40

Cowles, T. J., Olson, R. J., Chisholm, S. W. (1988). Food selection by copepods: discrimination on the basis of food quality. Mar Biol. 100: 41-49

Cowles, T. J., Strickler, J. R. (1983). Characterization of feeding activity patterns in the planktonic copepod Centropages typicus Kroyer under various food conditions. Limnol. Oceanogr. 28: 106-115

Dagg, M. (1977). Some effects of patchy food environments on copepods. Limnol. Oceanogr. 22: 99-107

Fenchel, T., Finlay, B. J. (1983). Respiration rates in heterotrophic, free-living Protozoa. Microb. Ecol. 9: 99-122

Frost, B. W. (1972). Effects of size and concentration of food particles on the feeding behaviour of the marine planktonic copepod Calanus pacificus. Limnol. Oceanogr 17 : $805-815$

Gifford, D. J., Dagg, M. J. (1988). Feeding of the estuarine copepod Acartia tonsa Dana: carnivory vs. herbivory in natural microplankton assemblages. Bull. mar Sci. 49: $458-468$

Gill, C. W (1987). Recording the beat patterns of the second antennae of calanoid copepods, with a micro-impedance technique. Hydrobiologia 148: 73-78

Guillard, R. R. L. (1975). Culture of phytoplankton for feeding marine invertebrates. In: Smith, W. L., Chanley, M. H. (eds.) Culture of marine invertebrate animals. Plenum Publ. Corp., New York, p. 29-60

Jonsson, P. R. (1986). Particle size selection, feeding rates and growth dynamics of marine planktonic oligotrichous ciliates (Ciliophora: Oligotrichina). Mar Ecol. Prog. Ser. 33: $265-277$

Kierboe, T., Mohlenberg, F., Hamburger, K. (1985). Bioenergetics of the planktonic copepod Acartia tonsa: relation between feeding, egg production and respiration, and composition of specific dynamic action. Mar. Ecol. Prog. Ser. 26: 85-97

Kirk, K. L. (1985). Water flows produced by Daphnia and Diaptomus: Implications for prey selection by mechanosensory predators. Limnol. Oceanogr. 30: $679-686$

Koehl, M. A. R. Strickler, J. R. (1981). Copepod feeding currents: food capture at low Reynolds number Limnol. Oceanogr 26: 1062-1073

Légier-Visser, M. F., Mitchell, J. G., Okubo, A., Fuhrmann, J. A. (1986). Mechanoreception in calanoid copepods: a mechanism for prey detection. Mar Biol. 90: 529-535

Lonsdale, D. J., Heinle, D. R., Siegfried, C. (1979). Carnivorous feeding behavior of the adult calanoid copepod Acartia tonsa Dana. J. exp. mar Biol Ecol. 36: 235-248

Montagnes, D. J.S., Lynn, D. H., Roff, J. C., Taylor, W. D. (1988). The annual cycle of heterotrophic planktonic ciliates in the waters surrounding the Isles of Shoals, Gulf of Maine: an assessment of their trophic role. Mar. Biol. 99: 21-30

Ohman, M. D. (1988). Behavioral responses of zooplankton to predation. Bull. mar Sci. 43: 530-550

Paffenhöfer, G.-A., Stearns, D. E. (1988). Why is Acartia tonsa (Copepoda: Calanoida) restricted to nearshore environments? Mar. Ecol. Prog. Ser. 42: 33-38

Price, H. J. (1988). Feeding mechanisms in marine and freshwater zooplankton. Bull mar Sci. 43: 327-343

Price, H. J., Paffenhöfer, G.-A. (1985). Perception of food availability by calanoid copepods. Arch. Hydrobiol. (Beih. Ergebn. Limnol.) 21: 115-124

Roberts, A. M. (1981). Hydrodynamics of protozoan swimming. In: Levandowsky, M., Hutner, S. H. (eds.) 
Biochemistry and physiology of protozod. Vol. 4. Academic Press, New York, p. 5-66

Rosenberg. G. (1980). Filmed observations of filter-feeding in the marine planktonic copepod Acartia clausi. Limnol Oceanogr 25: 738-742

Sheldon, R. W., Nival, P., Rassoulzadegan, F. (1986). An experimental investigation of a flagellate-ciliate-copepod food chain with some observations relevant to the linear biomass hypothesis. Limnol. Oceanogr. 31: 184-188

Sokal, R. R., Rohlf, F. J. (1969). Biometry. W H. Freeman and Co., San Francisco

Stearns, D. E. (1986). Copepod grazing behavior in simulated natural light and its relation to nocturnal feeding. Mar Ecol. Prog. Ser. 30: 65-76

This article was presented by Dr T Kiorboe, Charlottenlund, Denmark
Stoecker, D. K., Egloff, D. A. (1987). Predation by Acartia tonsa Dana on planktonic cliates and rotifers. J. exp. mar. Biol. 110: 53-68

Stoecker, D. K., Sanders, N. K. (1985). Differential grazing by Acartia tonsa on a dinoflagellate and a tintinnid. J. Plankton Res. 7: 85-100

Strickler, J. R. (1982). Calanoid copepods, feeding currents, and the role of gravity. Science, N. Y 218: 158-160

Tiselius, P. (1989). Contribution of aloricate ciliates to the diet of Acartia clausi and Centropages hamatus in coastal waters. Mar. Ecol. Prog. Ser. 56: 49-56

Wiadnyana, N. N., Rassoulzadegan, F. (1989). Selective feeding of Acartia clausi and Centropages typicus on microzooplankton. Mar. Ecol. Prog. Ser 53: 37-45

Manuscript first received: August 7, 1989

Revised version accepted: October 16, 1989 